\title{
Relation between content and composition of coalworkers' lungs and radiological appearances
}

\author{
C. E. ROSSITER \\ M.R.C. Pneumoconiosis Unit, Llandough Hospital, Penarth, Glamorgan
}

\begin{abstract}
Rossiter, C. E. (1972). Brit. J. industr. Med., 29, 31-44. Relation between content and composition of coalworkers' lungs and radiological appearances. The relation between radiological category of simple pneumoconiosis and dust content of the lung has been studied on a mixed group of 221 miners, of whom 76 had progressive massive fibrosis radiologically.

The average radiological scores based on 11 independent readings for the films showing simple pneumoconiosis only were related, by multiple regression, to the coal, mineral, quartz, and iron contents of the lungs. Three subgroups were found which showed differing relations. Films of poor technique tended to be read in the middle categories whatever the content of the lungs. The lungs of Scottish miners all contained soot, from working in naked light pits, and their radiological scores were much higher than expected from the lung dust contents. The few films showing nodular sized small opacities were also over-read, suggesting that nodularity may be some response to dust other than simple accumulation. There were 98 subjects in the resulting homogeneous group of cases with simple pneumoconiosis only. On a revised scale to correct for slight non-linearity, the regression coefficients of radiological score on the total mineral and coal contents of the lung were in the ratio of 3.8 to 1 . The iron content did not add much to this regression relation even though by itself it correlated well with the amount of simple pneumoconiosis. Probably most of the variation of radiological appearance with iron reflects variation with coal and mineral. The mineral and quartz contents were highly correlated $(r=0.96)$, but relations including quartz were not as close fitting as those including mineral. There was a small, but significant, residual relation of radiological score to years in coalmining.

The background categories of simple pneumoconiosis in the 76 radiographs showing some evidence of progressive massive fibrosis were generally read higher than expected from the relation to dust content derived from the simple pneumoconiosis cases only. This was most true for those showing most evidence of progressive massive fibrosis.
\end{abstract}

A series of 45 miners, almost exclusively from South Wales, was studied by Rivers, Wise, King, and Nagelschmidt (1960), who compared the radiological appearances of the miners' chest radiographs taken shortly before death with the dust composition and content of their lungs. Although other workers (King and Nagelschmidt, 1945; King, Maguire, and
Nagelschmidt, 1956; Faulds, King, and Nagelschmidt, 1959) had related content and composition of the dust to pathology, and Gough, James, and Wentworth (1949) had related radiological appearance to pathology, this was the first study relating radiological appearance to dust content and composition, and to pathology. 
Rivers and his colleagues (1960), on the original series of 45 coalworkers' lungs, showed that the mineral content of the lung contributed nine times as much as the coal content to the radiological appearance. When Rossiter and his colleagues (1967) extended this work to 88 cases the ratio of the contributions by the mineral and coal contents was reduced to $3: 1$. It was suggested that the discrepancy could be caused by the differing sources of cases as the original series was almost entirely from South Wales whereas Rossiter et al. included cases from other coalfields.

The other major difference was that the iron contents of the lungs were not available for all the series of Rivers and others, and Rossiter and his colleagues showed that there was also a marked relation of the iron content to the radiological appearance.

More recently, Vyskočil, Tůma, and Macek (1970) have related silica content to histological findings in the lungs of coalworkers, and Jacobsen, Rae, Walton, and Rogan (1970) and Reisner (1970) have related radiological findings to dust exposure in working British and German miners. There have also been attempts using phantoms to assess the radiological changes produced by dust, generally showing that the dust could be detected directly (Magnus et al., 1968; Gärtner and Sommer, 1967; Göbbeler et al., 1968).

Worth, Muysers, and Einbrodt (1968) and Einbrodt (1965) have shown that the grade of silicosis tends to increase with increasing total dust. Worth and his colleagues also concluded that pneumoconiotic shadows are not caused directly by inhaled dust but by a fibrous tissue reaction.

Rivers and his colleagues (1960) and Rossiter and his colleagues (1967) reported preliminary results on the early parts of the series. This paper is one of the series giving the full analyses on the dust content and composition of coalworkers' lungs (Gilson, Rae,

TABLE 1

Distribution OF THE COALWORKers by National Coal board Division and Whether Chest RADIOGRAPHS WERE AVAILABLE

\begin{tabular}{|c|c|c|c|c|}
\hline \multicolumn{2}{|c|}{ N.C.B. Division } & \multicolumn{2}{|c|}{$\begin{array}{c}\text { Chest radiographs } \\
\text { With Without }\end{array}$} & \multirow[b]{2}{*}{$\begin{array}{c}\text { Total } \\
110 \\
25 \\
32 \\
39 \\
35 \\
26 \\
55\end{array}$} \\
\hline $\begin{array}{l}\text { South Western } \\
\text { East Midlands } \\
\text { West Midlands } \\
\text { Northumberland \& } \\
\text { Yorkshire .. } \\
\text { North Western } \\
\text { Scottish . . }\end{array}$ & 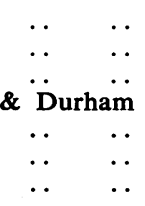 & $\begin{array}{r}108 \\
24 \\
31 \\
37 \\
35 \\
24 \\
50\end{array}$ & $\begin{array}{l}2 \\
1 \\
1 \\
2 \\
2 \\
5\end{array}$ & \\
\hline Total .. & .. & 309 & 13 & 322 \\
\hline
\end{tabular}

Nagelschmidt, and Rivers, 1971 ; Casswell, Bergman, and Rossiter, 1971; Bergman and Casswell, 1972; Bentley and Bergman, 1970; Bergman, 1970).

\section{Material and methods}

Table 1 lists the 322 coalworkers included in this study by the National Coal Board Division and whether recent chest radiographs were available (309) or not (13).

For these coalworkers industrial histories and chest radiographs were collected from the Pneumoconiosis Medical Panels and the National Coal Board. The coal content was assessed by the methods of King and Gilchrist (1945) or Bergman (1966); the mineral matter by the method of King and his colleagues (1956); the quartz content by the method of Gordon and Harris (1956); and the iron content by a method adapted from that of Cullen (1962). All the analytical determinations were carried out at the Safety in Mines Research Establishment, Sheffield. Pathological assessments of 'palpable nodules' were made by Dr. D. Rivers.

Full details of the sources of the material and the methods will be published by Gilson and his colleagues (in preparation).

\section{The problem}

Rivers and his colleagues (1960) commented that 'the method of obtaining the adjusted radiological scale is an unusual one improvised to meet an unusual difficulty. We needed a quantitative analysis without knowing what half of our quantities were, namely those depending on breadths of categories in the (original) radiological scale'. This difficulty still existed, but there was the further uncertainty of not knowing whether subgroups of the series would show differing or anomalous relationships of radiological appearance to dust content.

\section{Assessment of radiological appearance}

The radiographs were read by nine National Coal Board and two Medical Research Council film readers, each in a different random order. Two reading sessions were arranged with six film readers at each, but one N.C.B. reader was prevented by snow from attending either session.

Simple pneumoconiosis was read according to the N.C.B. elaboration (Liddell and Lindars, 1969) of the International Labour Office 1958 Geneva classification (I.L O., 1959). The effect of this elaboration is to make the I.L.O. classification more sensitive by subdividing each category into three parts according to the instructions given by Liddell and Lindars:

'Please record the (I.L.O.) category into which you would classify the film following the normal convention. If, in the course of that classification, you considered an adjacent category as a serious possibility please record that category (after an oblique stroke); otherwise, please repeat the I.L.O. category (after a stroke).

'Barn-door' normals, i.e., films over which you have no trace of doubt that they are normal, should be recorded as $0 /$. . If a film shows evidence of so much dust retention that you consider there can be no doubt it would always be read as category 3 , enter $3 / 4$.'

Thus, the full 12 -point scale is $0 /-, 0 / 0,0 / 1,1 / 0,1 / 1,1 / 2$, 
$2 / 1,2 / 2,2 / 3,3 / 2,3 / 3,3 / 4$. The size of the opacities, punctiform, micronodular or nodular, and the extent of progressive massive fibrosis (P.M.F.) (A, B or C and an extra symbol $X$ to indicate shadows which were thought to show the earliest stages of P.M.F.) were also read according to the Geneva classification.

Each of the 11 film readers read the category of simple pneumoconiosis for 233 of the 309 radiographs. At least one reader recorded that the category of simple pneumoconiosis was unreadable in the remaining 76 films, in a majority of cases because there were large opacities (P.M.F.) which were too extensive to permit assessment of the background pattern of simple pneumoconiosis. Table 2 lists, by N.C.B. division and by readings of P.M.F., these 76 films, which have been put into three groups: no reading of P.M.F.; up to three readings of $\mathrm{A}, \mathrm{B}$ or $\mathrm{C}$; and four or more readings of $\mathrm{A}, \mathrm{B}$ or $\mathrm{C}$.

The scoring system developed below is based on this series of 233 coalworkers' films, for each of which all 11 readings of simple pneumoconiosis were available. However, of these 233 coalworkers, the industrial histories or lung analyses were incomplete in 12 cases. All the further statistical analysis of radiological appearance, the industrial histories, and the lung content and composition are based on the 221 coalworkers with all radiological readings and complete industrial histories and lung analyses.

Derivation of scores for the categories of simple pneumoconiosis

Before any estimate may be made of the effect dust in the lungs has on radiological appearance, some means of averaging the $x$-ray readings is needed. To use an agreed reading has been suggested, but Liddell (1963) and Wise and Oldham (1963a) have shown that this is inefficient compared with an average, on some suitable scale, of all the readings.

Wise, in Rivers et al. (1960) (Appendix A), suggests that radiological change is a continuous variable and is normally distributed for populations of faceworkers on a new scale $y$, where

$$
y=1+\frac{1}{4}\left(x^{2}-\frac{1}{x^{2}}\right)
$$

and $x$ is the radiological continuum taking the values 1 at the boundary between categories 0 and 1,2 at the category 1 - category 2 boundary, and 3 at the category 2 -category 3 boundary.

If this is so, then plotting on probability graph paper the proportions of coalface workers with category 0 , category 1 or less, and category 2 or less simple pneumoconiosis against the $y$ scale defined above will give a straight line relation.

In Fig. 1, these proportions are plotted for each of the 11 readers. It can be seen that each of the lines corresponding to the 11 readers is acceptably straight, allowing for random variation, and the horizontal displacements of these lines show how much bias exists between the readers; for example, when the reader who 'under' read most (the top line) considered a film to be about on the category 0 category 1 boundary, then the reader who 'over' read most would have considered it to be about one-third of the way through category 2. However, these biases tended to be consistent throughout the range of readings as shown by the lines being nearly parallel so that all the readings have been combined.

In Fig. 2 the cumulative distribution for the 11 readers combined is plotted against the $y$ scale. The $0-1,1-2$, and 2-3 category boundaries are shown as the spots which lie remarkably close to a straight line. Using this straight line, the boundaries on the $y$-scale between the subcategories of the National Coal Board elaboration of the Geneva classification may be determined. For example, $45.9 \%$ of all the readings were subcategory $1 / 1$ or less. Tracing the $45.9 \%$ point across to the straight line and then down gives $y=1.62$ as the boundary between subcategories $1 / 1$ and $1 / 2$. Table 3 gives these boundaries for each subcategory. The calculations for the derivation of the scores are also given in Table 3 . For example, the boundary between subcategories $1 / 0$ and $1 / 1$ is $1 \cdot 24$, and that between $1 / 1$ and $1 / 2$ is $1 \cdot 62$. Hence the midpoint of subcategory $1 / 1$ is 1.43 and the range is 0.38 . The midpoint of subcategory $0 /$ - is taken at the $y$-value corresponding to $2.8 \%$ (half of $5.6 \%$ ) as $5.6 \%$ of all the readings were $0 /-$, the range is then twice the difference between this midpoint and the value of $y$ at the boundary with $0 / 0$. A similar calculation gives the midpoint and range for subcategory $3 / 4$.

The weighting co-efficients given for each score are inversely proportional to the range, and the average score for any film is the weighted average of the scores for the

TABLE 2

Distribution of Readings by 11 Readers of Progressive Massive Fibrosis for 76 Films, for which at least One Reader did not Record the Category of Simple PNeumoconiosis

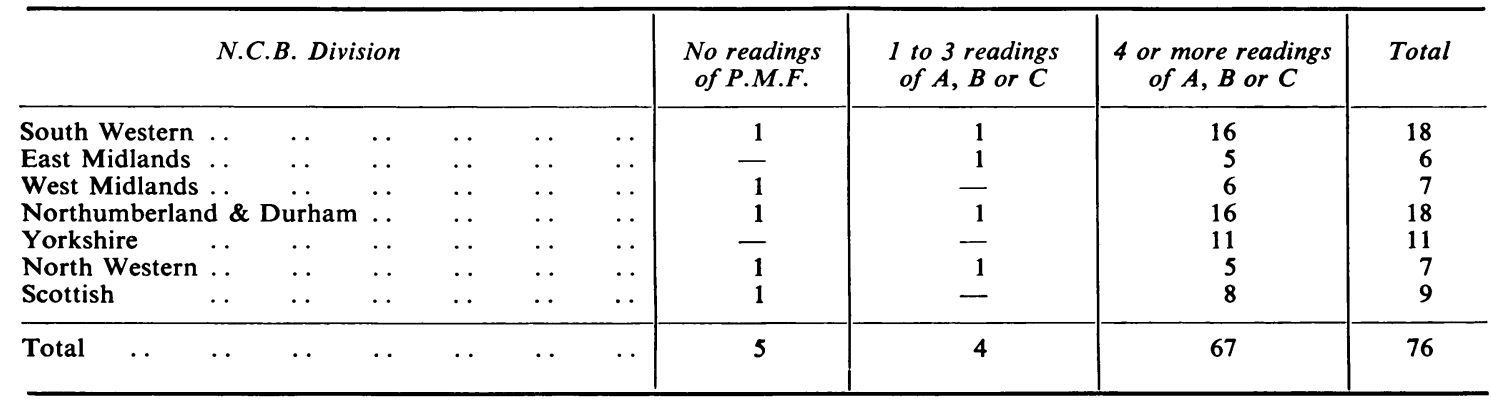



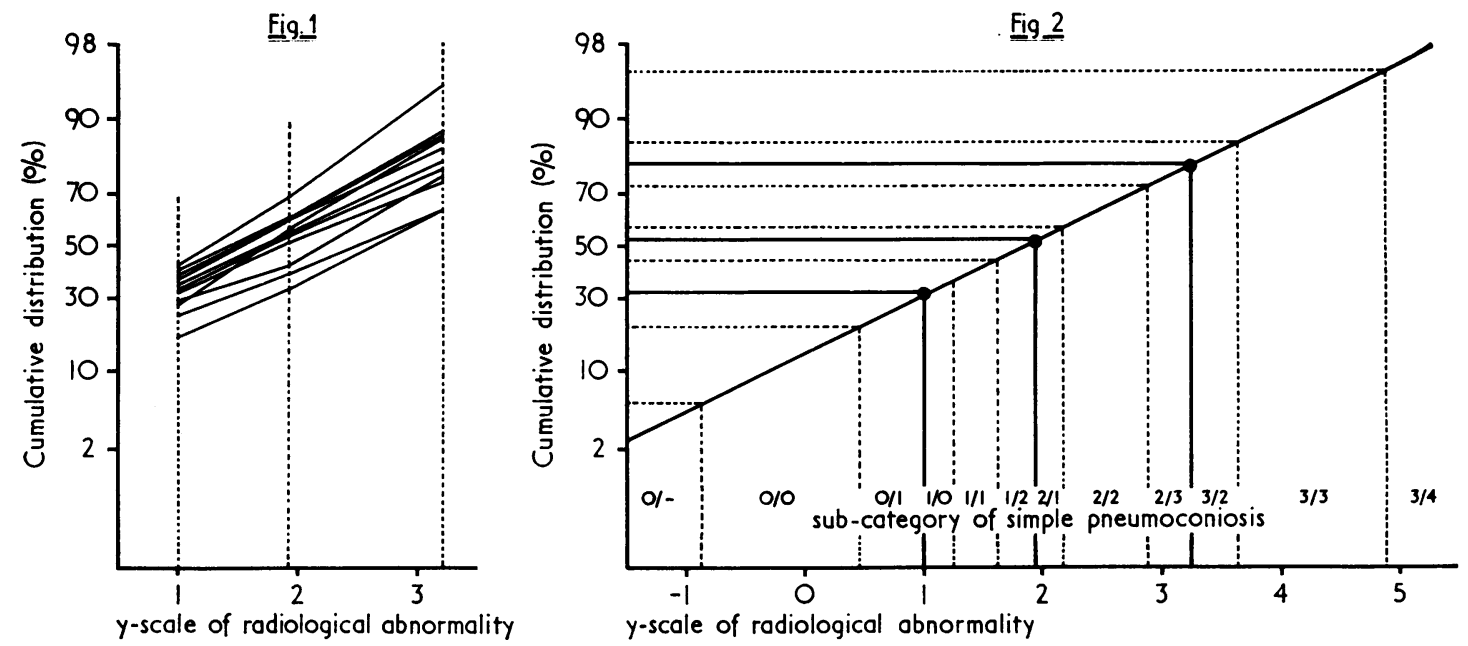

FIG. 1. Cumulative distribution for each film reader of his readings of simple pneumoconiosis in 233 radiographs.

FIG. 2. Derivation of boundaries between subcategories on the radiological abnormality scale.

individual readings of that film. For example, if there were only two readers, and they read one film as $1 / 2$ and $2 / 1$, then the average score would be

$$
\frac{1.78 \times 3.125+2.04 \times 5.000}{3.125+5.000}=1.94
$$

Thus the average score is the boundary point between these subcategories $1 / 2$ and $2 / 1$. This is true for two readings of any adjacent subcategories and is obviously a necessary property of an acceptable scoring system. This scoring system also gives more weight to a reading of a narrow subcategory. This is appropriate, for such a reading places the radiograph more precisely on the scale of radiological change.
The average scores from all 11 readings for each film are similarly calculated. For none of the films did all 11 readers agree on the subcategory of simple pneumoconiosis, there being most agreement at either end of the scale of abnormality.

There were, however, 19 films for which the range of readings was at least from $0 / 1$ to $3 / 2$. Of these 19 films, eight showed linear markings, whereas only one of a control set of 32 films showed such markings. This suggests that if linear markings are present on a radiograph, forcing the reading into one of the subcategories of simple pneumoconiosis (small round opacities) is not necessarily appropriate, and that readers will disagree markedly about that film. That this is now recognized as

TABLE 3

Derivation of Scores and Weights for Each Subcategory of Simple PNeumoconiosis from Boundaries BETWEEN THE SUBCATEGORIES

\begin{tabular}{|c|c|c|c|c|c|}
\hline $\begin{array}{l}\text { I.L.O. category } \\
\text { of simple } \\
\text { pneumoconiosis }\end{array}$ & $\begin{array}{c}\text { Subcategory } \\
\text { of simple } \\
\text { pneumoconiosis }\end{array}$ & Boundary & Midpoint & Range & $\begin{array}{l}\text { Weighting } \\
\text { coefficient }\end{array}$ \\
\hline 0 & $\begin{array}{l}0 /- \\
0 / 0 \\
0 / 1\end{array}$ & $\begin{array}{r}-0.88 \\
0.44 \\
1.00\end{array}$ & $\begin{array}{r}-1.44 \\
-0.22 \\
0.72\end{array}$ & $\begin{array}{l}1.12 \\
1.32 \\
0.56\end{array}$ & $\begin{array}{l}0.893 \\
0.758 \\
1.786\end{array}$ \\
\hline 1 & $\begin{array}{l}1 / 0 \\
1 / 1 \\
1 / 2\end{array}$ & $\begin{array}{l}1.24 \\
1.62 \\
1.04\end{array}$ & $\begin{array}{l}1.12 \\
1.43 \\
1.78\end{array}$ & $\begin{array}{l}0.24 \\
0.38 \\
0 \cdot 32\end{array}$ & $\begin{array}{l}4 \cdot 167 \\
2 \cdot 632 \\
3 \cdot 125\end{array}$ \\
\hline 2 & $\begin{array}{l}2 / 1 \\
2 / 2 \\
2 / 3\end{array}$ & $\begin{array}{l}2 \cdot 14 \\
2 \cdot 86\end{array}$ & $\begin{array}{l}2 \cdot 04 \\
2 \cdot 50 \\
3 \cdot 04\end{array}$ & $\begin{array}{l}0.20 \\
0 \cdot 72 \\
0 \cdot 36\end{array}$ & $\begin{array}{l}5.000 \\
1 \cdot 389 \\
2 \cdot 778\end{array}$ \\
\hline 3 & $\begin{array}{l}3 / 2 \\
3 / 3 \\
3 / 4\end{array}$ & $\begin{array}{l}3 \cdot 22 \\
3.62 \\
4.86\end{array}$ & $\begin{array}{l}3 \cdot 42 \\
4 \cdot 24 \\
5 \cdot 36\end{array}$ & $\begin{array}{l}0.40 \\
1.24 \\
1.00\end{array}$ & $\begin{array}{l}2 \cdot 500 \\
0 \cdot 806 \\
1.000\end{array}$ \\
\hline
\end{tabular}


important is shown by the recent development of the UICC/Cincinnati classification of radiographic appearances of pneumoconioses (1970), in which linear or irregular markings are classified separately from the opacities usually seen in coalworkers' pneumoconiosis.

Weights to be attached to the average score for each radiograph

Just as the reading of a narrow subcategory carries more information than the reading of a wider subcategory, so the more agreement there is between readers the more information that film provides in the relation between radiological appearance and any other factor.

The weight (not to be confused with the weighting coefficient for the subcategory of simple pneumoconiosis in Table 3 ) is the inverse of the sum of squares of the scores for the readings of simple pneumoconiosis. Thus the more the scatter of readings, the lower the weight for that film.

The effect of this is largely to give more weight to films showing very little or very much simple pneumoconiosis, that is films about which the readers tended to agree, and less weight to films showing intermediate degrees of simple pneumoconiosis. There are, of course, considerable variations in weights about this general pattern.

These weights have been consistently used in all the following analyses. However, the effect of giving each point equal weight, ignoring the amount of information it provides, has been examined. The conclusions are unaffected although all the estimates are less precise. Typically the residual variance about a regression line is increased by about $50 \%$.

\section{Results}

The scoring method for the reading of the radio- graphs was based on the radiographs of 233 miners, but 12 had incomplete industrial histories or lung analyses. The following analyses are therefore based on the remaining 221 miners, and the distribution of these cases by the various qualitative factors to be considered later is given in Table 4.

It is not known which subgroups of miners are likely to show consistent and which differing, relations to dust content of the lung, so the first analyses have been restricted to those with simple pneumoconiosis only. Of the 221 miners, 145 had simple pneumoconiosis only, that is, no reader recorded P.M.F.; for 23, up to three readers recorded $X$, that is suspect P.M.F.; for 18, up to three readers recorded $\mathrm{A}, \mathrm{B}$ or $\mathrm{C}$; and for the remaining 35 , four or more readers recorded $\mathrm{A}, \mathrm{B}$ or C.

\section{Simple pneumoconiosis}

Figure 3 shows for the 145 miners with simple pneumoconiosis only how the average values for the coal, total mineral, quartz, and iron contents of the one lung analysed varied with radiological subcategory (based on the readings of both lungs). For each there is a reasonably consistent pattern of increasing content of the lung with increasing subcategory of simple pneumoconiosis.

The patterns for the total mineral and quartz contents are almost indistinguishable, except for scale. This is not unexpected as the correlation between them is 0.958 . Thus for many analyses quartz and total minerals may be used interchangeably. As shown by Bergman and Casswell (1972), quartz is not a constant proportion of the mineral dust, the ratio varying with the rank of coal mined,

TABLE 4

Distribution of 221 Cases with Complete Information, by National Coal Board Division and Certain Qualitative Factors

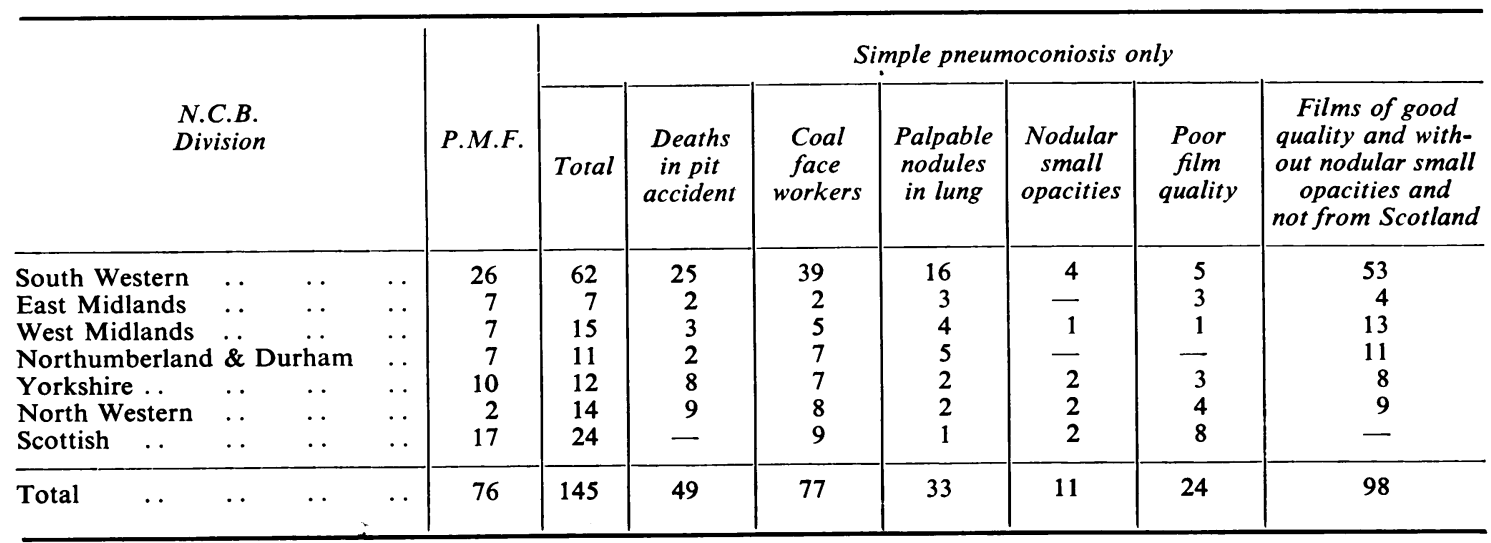




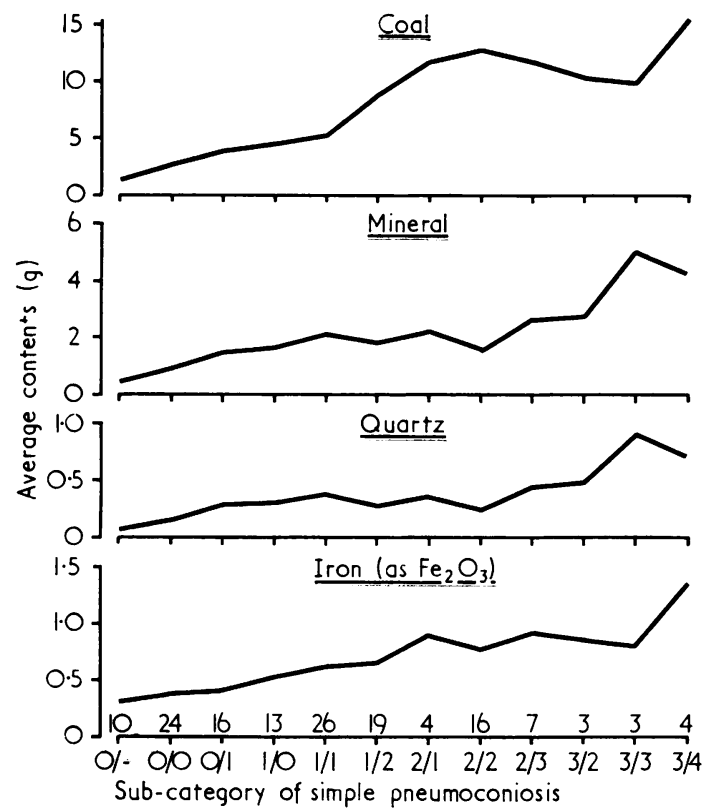

FIG. 3. Average contents of one lung (grams): 145 miners without P.M.F.

so that part of this very high correlation may be an artifact.

Examination of these patterns in Fig. 3 for coal and total minerals shows a certain interesting interrelation. The two curves both rise gently initially, but when the slope for coal is steeper (between 1/1 and 2/2) that for minerals is virtually zero. Following this, the fall in the averages for coal is accompanied by a rise for minerals between $2 / 2$ and $3 / 3$. Finally, there is a sharp rise for coal and a sharp fall for minerals. Throughout, whenever the slope of the relation between average coal content and subcategory is greater than the initial slope, then that for minerals is less and vice versa. This suggests that some average or combination of the two would relate to category of simple pneumoconiosis much better than either does separately.

Preliminary multiple regression analysis The most useful initial approach to considering the relation between radiological score and the coal, mineral, and iron contents of the lung is the multiple regression approach. The results of this multiple regression for the 145 miners with simple pneumoconiosis, however, show that there are three subgroups for each of which the distribution of radiological scores differs from that for the main group.

Effect of radiographic technique Each of the 11 film readers made a note whenever he considered that the film quality was unsatisfactory. There were 22 films for which over half of the readers considered the film quality to be unsatisfactory, and it is apparent that there is a tendency for the observed radiological scores for these 22 films to lie between 1 and 3, that is, approximately in categories 1 and 2 irrespective of the predicted radiological score. This accords with the finding by Wise and Oldham (1963b) that the extreme categories 0 and 3 were read proportionately more often on acceptable films than on imperfect films in a study on 687 pairs of chest radiographs.

Effect of opacity size Rossiter and his colleagues (1967) showed a relation between size of small opacity and radiological score such that the larger the opacity size the greater was the expected radiological score. In this series, no association between opacity size and radiological score is detectable except for the few films with nodular opacities. There were 11 films for which at least one reader said that the opacities were nodular in size, and for 10 of these 11 the observed radiological score is greater than the predicted, suggesting that either films with the larger opacities are over-read or a nodular pattern is evidence of some response to dust other than simple accumulation.

Not one of these 11 cases had a quartz content of the total lung dust greater than $10 \%$, but they did have a slightly higher average quartz proportion $(4.5 \%)$ than did the other 134 subjects $(3.4 \%)$. However, the quartz content of the mineral dust was not higher for 10 of these 11 cases than for the other 134 cases. There were also in the full series a further 16 subjects with P.M.F. and a radiograph which at least one reader recorded as showing nodular small opacities. Six of these 16 had quartz contents of the total lung dust between $12 \%$ and $15 \%$, and their average quartz proportion was $6 \cdot 1 \%$.

Differences between coalfield divisions Although there are not enough miners from some of the English coalfields to show differences between them, there is no evidence of bias, of consistent under- or over-reading, for the subjects who worked in England. Similarly, there is no evidence of bias for the South Wales miners.

However, for Scotland, the observed radiological score was above that predicted for 19 of the 24 subjects. A major difference between these lungs and those from the rest of Britain is that the Scottish lungs all contained soot, and Bentley and Bergman (1970) reported that this was related to mining in naked-light pits. The chemical determinations included the soot as part of the coal content of the lungs.

Main multiple regression analyses One main 
problem in this analysis was to discover which subgroups were homogeneous and which showed some other relation to dust accumulation in the lung. The initial analyses have shown that lungs from Scottish miners and films showing nodular opacities or of poor technique should be excluded as heterogeneous. This leaves 98 subjects in the analyses, of whom 53 were from South Wales, 4 from East Midlands, 13 from West Midlands, 11 from County Durham, 8 from Yorkshire, and 9 from Lancashire. All these 98 were subjects with simple pneumoconiosis only, in that not one of the 11 readers recorded P.M.F. or suspect P.M.F.; each had a radiograph which the majority of readers recorded as satisfactory and there were no readings of nodular small opacities.

Repeating the multiple regression analysis with these 98 subjects only gives

Radiological score $=$

$$
\begin{aligned}
-0.9065 & +B_{c} \times \text { coal }+B_{m} \times \underset{\text { mineral }}{ }+B_{i} \times \text { iron }
\end{aligned}
$$

where $B_{c}=0 \cdot 1279 \pm 0 \cdot 0160$

$B_{m}=0.5382 \pm 0.0545$

$B_{i}=-0.0777 \pm 0.4812$

The multiple correlation coefficient is $\mathbf{0 . 8 9}$.

Figure 4 shows the relation between the observed radiological score and that predicted by this equation. It is apparent that this is not a linear relation, as low observed values tend to be less than predicted whereas the trend is reversed in the middle of the relation.

This raises the problem that the shape of the true response of radiological change to dust is not known. The assumption has been made that the radiological score should be linearly related to the dust contents of the lungs. To satisfy this, the radiological score scale must be transformed.

The observed and predicted radiological scores have been ranked separately, and then the pairs ranked the same have been plotted together in Figure 5. Thus the lowest point corresponds to the lowest observed radiological score plotted against the lowest predicted radiological score, and so on. An arbitrary smooth curve was drawn through these points and this curve was then used to transform the observed radiological score scale.

The multiple regression relation using this revised radiological score is given by

Revised radiological score $=$ $-0.8385+b_{c} \times$ coal $+b_{m} \times$ mineral

$$
\text { where } \begin{aligned}
b_{c} & =0.1178 \pm 0.0144 \\
b_{m} & =0.4557 \pm 0.0488 \\
b_{i} & =0.1697 \pm 0.4311
\end{aligned}
$$$$
+ \text { bi } \times \text { iron }
$$

The observed revised radiological scores are plotted against those predicted from this equation in Figure 6. This relation does not show the curvature which occurred using the original radiological score.

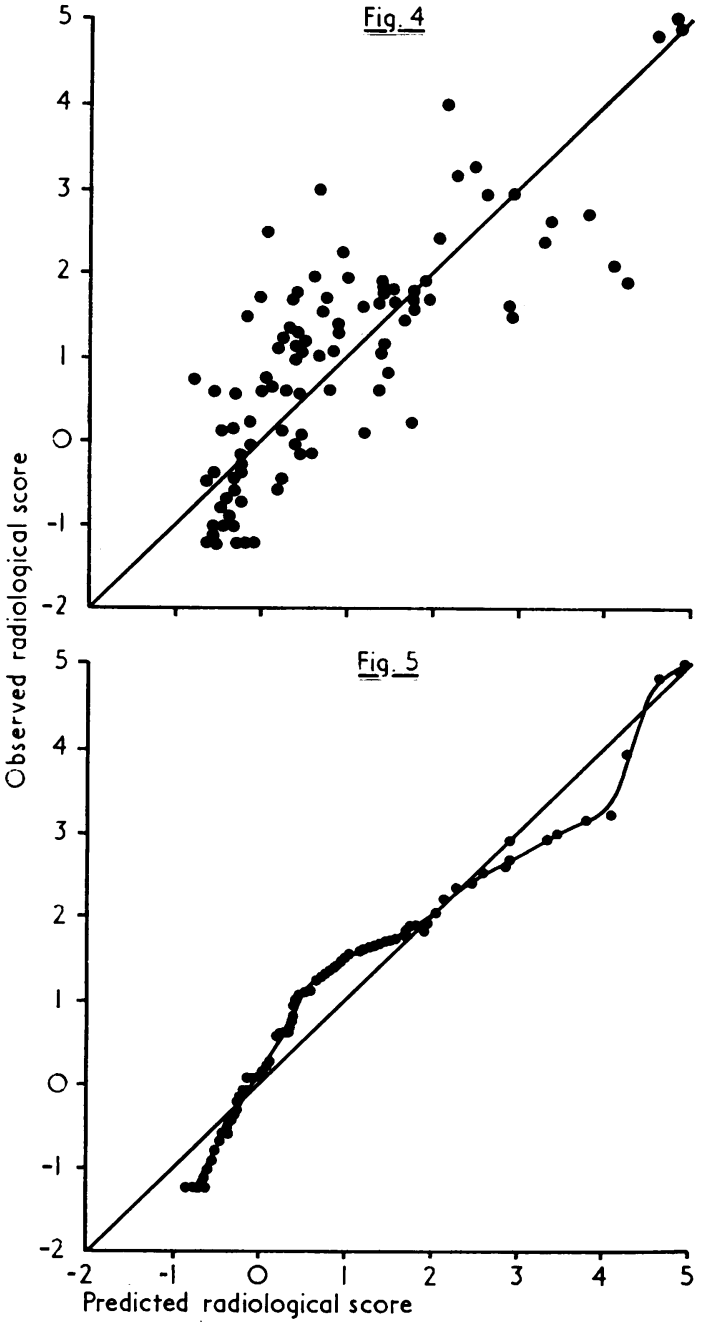

FIG. 4. Observed radiological score and that predicted from the relation to the coal, mineral, and iron contents of the lungs: 98 miners with simple pneumoconiosis only and from England and Wales only.

FIG 5. Linearizing transformation of radiological score scale, based on ranked pairs of observed and predicted radiological scores (from Fig. 4).

Repeating the ranking procedure gives a virtually straight line between the ranks, so no further transformation is needed.

Table 5 gives the boundaries between the subcategories for the original radiological score scale, the revised boundaries, and the number in each subcategory together with the average values for the coal, mineral, quartz, and iron contents of one lung. 


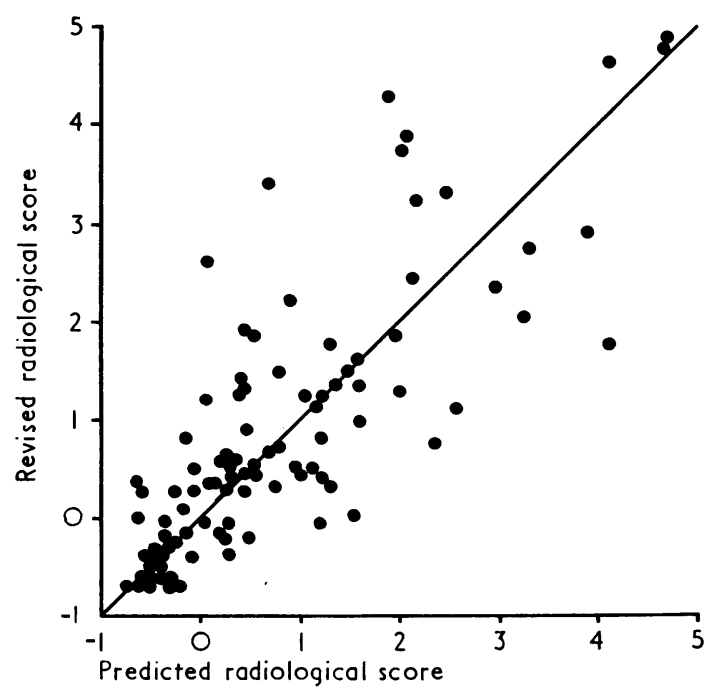

FIG. 6. Relation between revised radiological score and that predicted from the coal, mineral, and iron contents of one lung: 98 miners with simple pneumoconiosis only and from England and Wales only.

Neither for this analysis nor for the previous analysis using the untransformed scores does iron contribute significantly or materially to the regression relation. This result differs from that published by Rossiter and his colleagues (1967) and from that using all 145 miners with simple pneumoconiosis. Table 5 also shows that there is a definite relation between the revised radiological score and iron content of the lung.
However, for this group the relation between iron and the coal and mineral contents is

Iron content $\left(\right.$ as $\left.\mathrm{Fe}_{2} \mathrm{O}_{3}\right)=0.2272+0.0227$

$\times$ coal content $+0.0772 \times$ mineral content

Both these regression coefficients are highly significant $(t=9.1$ and 6.7) and the multiple correlation coefficient is $\mathbf{0 . 7 8}$. If, after allowing for variation with coal and mineral contents, any residual variation in iron content is uncorrelated with radiological score, particularly if it is just random, then no relation of radiological score to iron content would be expected in any multiple regression analysis also including the coal and mineral contents.

The constant term of $0.23 \mathrm{~g}$ of iron, expressed as $\mathrm{Fe}_{2} \mathrm{O}_{3}$, agrees well with the $0 \cdot 2$ to $0.25 \mathrm{~g}$ occurring in non-pneumoconiotic lungs and coming from the blood analysed with the lungs. This relationship above suggests that most of the remaining iron might arise as a response to the deposition of dust. Collet, Martin, Normand-Reuet, and Policard (1967) have shown iron, probably as ferritin, coating dust particles in the lung. They suggest that the iron is definitely endogenous and perhaps results from phagocytosis. This evidence would indicate that the iron content may be related to the surface area of the particles. It is almost impossible to compare directly the surface areas of particles retained in the lungs. However, over the range of size distributions found for airborne coal and rock dust clouds (Cartwright, 1965; Burdekin and Dawes, 1958) and considering the elutriation effect of the lungs, coal dust has a surface area per unit weight between $40 \%$ and $80 \%$ larger than that of rock dust. This does assume, though, that the particle shapes are the same and that the biologically active surface area is the same as the actual surface area.

TABLE 5

Effect of Transformation of Radiological Score Scale on Boundaries between the Subcategories of Simple PNeumoconiosis and Average Values for Lung Contents for the Main Group ANALYSED

\begin{tabular}{|c|c|c|c|c|c|c|c|}
\hline \multirow{2}{*}{$\begin{array}{l}\text { Sub-category } \\
\text { of simple } \\
\text { pneumoconiosis }\end{array}$} & \multirow{2}{*}{$\begin{array}{c}\text { Original } \\
\text { boundary }\end{array}$} & \multirow{2}{*}{$\begin{array}{c}\text { Boundary on } \\
\text { revised } \\
\text { radiological } \\
\text { score scale }\end{array}$} & \multirow{2}{*}{ No. } & \multicolumn{4}{|c|}{ Average values for contents of one lung $(g)$} \\
\hline & & & & Coal & $\begin{array}{c}\text { Total } \\
\text { minerals }\end{array}$ & Quartz & $\begin{array}{c}\text { Iron } \\
\left(\text { as } \mathrm{Fe}_{3} \mathrm{O}_{3}\right)\end{array}$ \\
\hline $\begin{array}{l}0 /- \\
0 / 0 \\
0 / 1 \\
1 / 0 \\
1 / 1 \\
1 / 2 \\
2 / 1 \\
2 / 2 \\
2 / 3 \\
3 / 2 \\
3 / 3 \\
3 / 4\end{array}$ & $\begin{array}{r}-0.88 \\
0.44 \\
1.00 \\
1.24 \\
1.62 \\
1.94 \\
2.14 \\
2.86 \\
3.22 \\
3.62 \\
4.86\end{array}$ & $\begin{array}{r}-0.53 \\
0.14 \\
0.45 \\
0.63 \\
1.22 \\
1.90 \\
2.14 \\
3.18 \\
3.85 \\
4.21 \\
4.76\end{array}$ & $\begin{array}{r}10 \\
23 \\
12 \\
9 \\
13 \\
15 \\
1 \\
6 \\
4 \\
1 \\
2 \\
2\end{array}$ & $\begin{array}{r}1.3 \\
2.7 \\
3.8 \\
5.2 \\
5.2 \\
9.7 \\
26.1 \\
18.0 \\
10.1 \\
15.2 \\
11.8 \\
17.9\end{array}$ & $\begin{array}{l}0.41 \\
0.95 \\
1.28 \\
1.54 \\
2.39 \\
1.97 \\
1.82 \\
1.70 \\
2.96 \\
2.10 \\
4.98 \\
7.03\end{array}$ & $\begin{array}{l}0.07 \\
0.14 \\
0.23 \\
0.26 \\
0.45 \\
0.28 \\
0.24 \\
0.26 \\
0.54 \\
0.34 \\
0.88 \\
1 \cdot 13\end{array}$ & $\begin{array}{l}0.30 \\
0.35 \\
0.34 \\
0.48 \\
0.57 \\
0.61 \\
1.61 \\
0.65 \\
0.79 \\
1.02 \\
0.98 \\
0.91\end{array}$ \\
\hline
\end{tabular}


When the relation between iron and the coal and mineral contents is examined for the remaining 47 cases with simple pneumoconiosis excluded from this analysis, it is very different from the above equation. This arises presumably because the Scottish lungs contained soot and this was in very fine particulate form (Bentley and Bergman, 1970). The surface area per unit weight was probably a little larger than that for coal, and the Scottish lungs did have twice as much iron as expected from the overall relation between iron and the coal and mineral contents. This adds a little support to the surface area theory.

It is probable that the significant regression coefficient for iron reported before occurred from the mixing of heterogeneous data. As may be seen from Fig. 7, the relations between iron and the revised radiological score for the main group and for Scotland are quite different, and this holds even if the outlying Scottish point is excluded. This difference also exists between the partial regression coefficients, after allowing for the coal and mineral contents.

Relation between revised radiological score and coal and mineral content only This relation for the pure group only is

Revised radiological score $=0.7981+b_{c} \times$ coal content of one lung $+b_{m} \times$ mineral content of one lung

where $b_{c}=0.1215$ with standard error 0.0107

$b_{m}=0.4671$ with standard error 0.0382

The multiple correlation coefficient $=\mathbf{0} \cdot 90$.

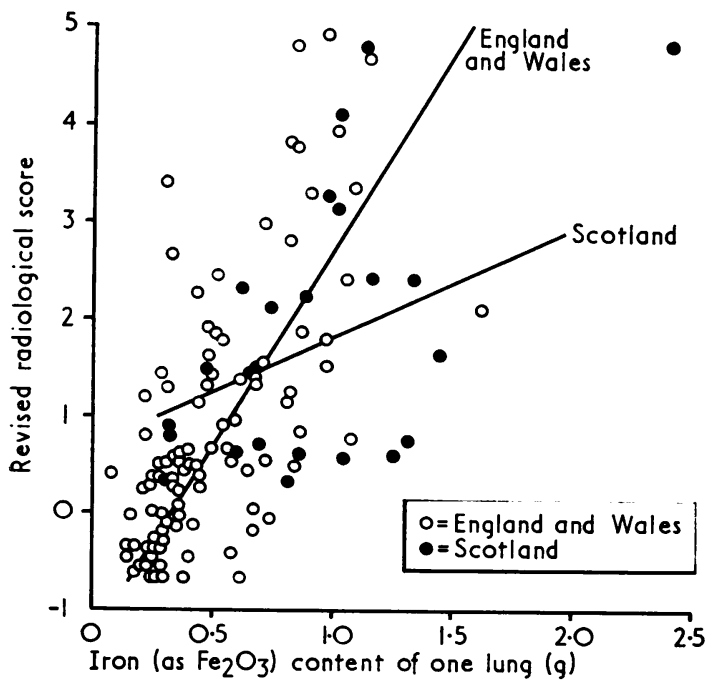

FIG. 7. Regressions for England and Wales and for Scotland of revised radiological score on iron content of the lung.
The constant term, -0.7981 , suggests that one would expect a person with no dust exposure to have a revised radiological score of -0.7981 . The revised radiological score for a film read by all readers as a barndoor normal (subcategory $0 /-$ ) would be -0.75 , which is remarkably close.

The ratio of the regression coefficients for mineral and coal contents is $3 \cdot 8: 1$, a little higher than the value of $3 \cdot 3: 1$ reported before by Rossiter and his colleagues (1967), and the 3.3:1 ratio for the $x$-ray mass absorption coefficients for mineral and coal (S.M.R.E., 1963). However, the $95 \%$ fiducial limits for this ratio of the regression coefficients are $3 \cdot 3: 1$ and $4 \cdot 5: 1$.

Thus, this relation is the simplest expression, in terms of regression, of the relation between radiological score and dust contents of the lungs for simple pneumoconiosis cases only. It is also the best in the sense that identifiable subgroups which show a different relation have been excluded.

The excluded subgroups In Fig. 8, the observed revised radiological scores for the films with poor technique are plotted against the expected scores based on the above relation. The scatter of the results appears to be rather increased and this is confirmed as the ratio of the variance of the difference between observed and expected for this poor technique group to the variance about the regression line for the main group is 3.5:1 (P $<0.001)$.

Figures 9 and 10 show the same plots of revised radiological scores against those expected for the Scottish and nodular subgroups. In both cases the radiological scores are considerably higher than expected. For Scotland, particularly for the 16 films with simple pneumoconiosis only, there appears to be a strong linear relation between observed and expected. The actual relation between the revised radiological score and the dust contents shows a small non-significant regression coefficient for iron, but the regression coefficients for coal and mineral contents are twice and three times those for the main group, and the difference between the two regression lines is highly significant $(P<0.001)$.

Effect of replacing mineral by quartz in analyses The regression of revised radiological score on coal and quartz only is

Revised radiological score $=$

$$
-0.7525+B_{c} \times \text { coal }+B_{q}+\text { quartz }
$$

where $B_{c}=0.1349 \pm 0.0107$

and $B_{q}=2 \cdot 3402 \pm 0.2034$

Neither the constant term nor the regression coefficient on coal are much changed, but the multiple correlation coefficient is reduced slightly to $\mathbf{0 . 8 8}$. This reduction in the multiple correlation coefficient, and the corresponding increase in the scatter of the relation between observed and predicted radiological 


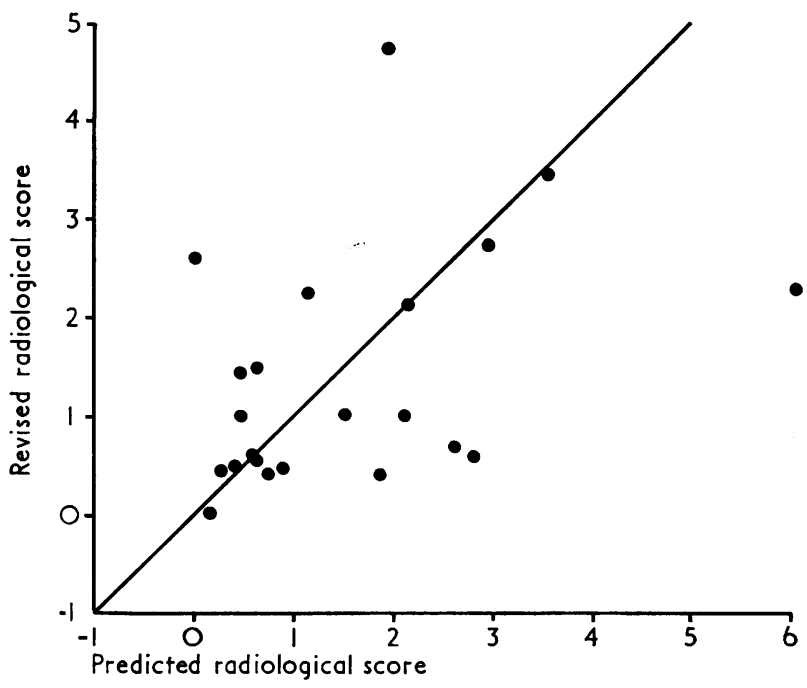

FIG. 8. Comparison of revised radiological scores with those predicted from the relation to the coal and mineral contents of the lungs (based on simple pneumoconiosis cases only). Technically poor films.

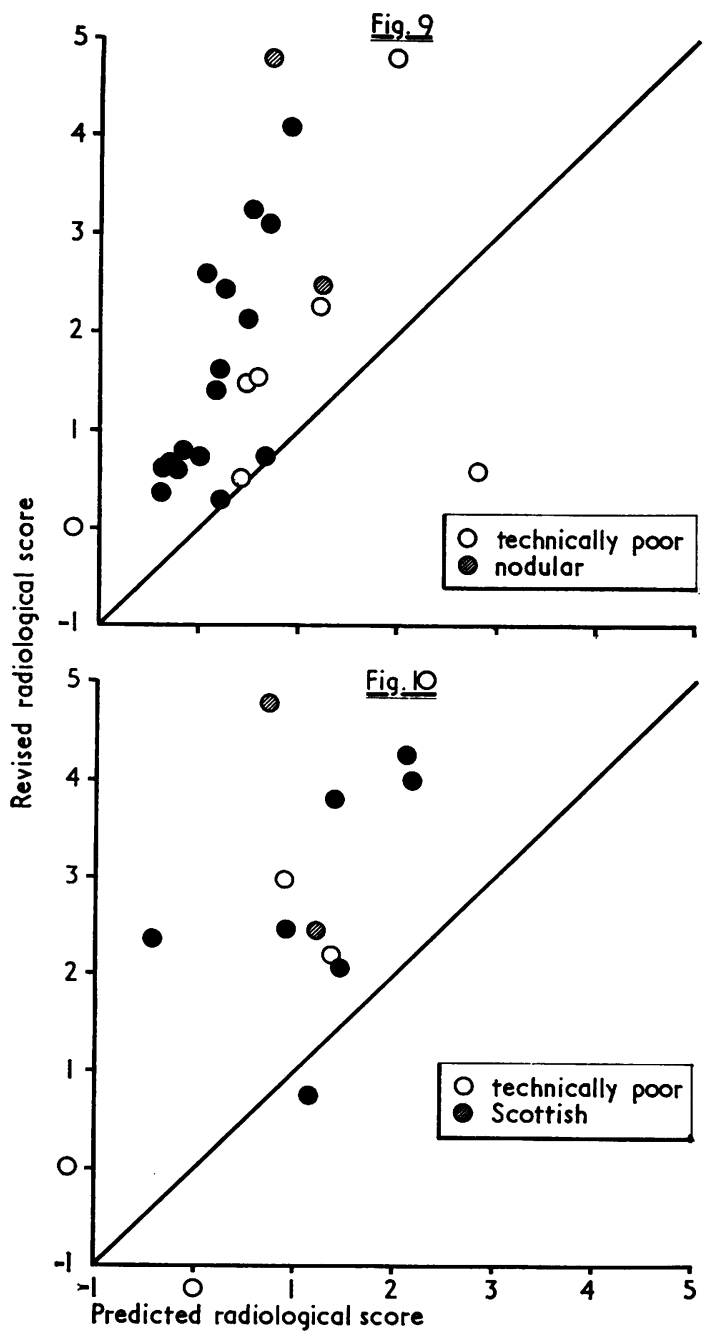

scores, is very little. However, without exception every analysis has shown a slightly closer relation when mineral, rather than quartz, has been included in the analysis.

If minerals and quartz are both included in an analysis, then usually the regression coefficient on quartz is very small and slightly negative, whereas that for minerals is hardly changed.

Relation to other variables There are several other variables which may be related to radiological appearance and so may increase the accuracy of the prediction of the revised radiological score.

To assess this, the values of each variable have been plotted against the corresponding weighted residual differences between the observed scores and those predicted from the relation to coal and mineral contents.

(a) Total years of exposure These have been plotted against the differences in Figure 11. There appears to be a slight positive correlation, and an analysis shows that the partial correlation coefficient is $0.22(P<0.05)$. The inclusion of total years of exposure to the regression equation thus reduces the scatter about the regression line significantly but not materially, as the reduction in the residual variance is only $4.6 \%$. The partial regression coefficient of

FIG. 9. Comparison of revised radiological scores with those predicted from the relation to the coal and mineral contents of the lungs (based on simple pneumoconiosis cases only). Films of Scottish miners.

FIG. 10. Comparison of revised radiological scores with those predicted from the relation to the coal and mineral contents of the lungs (based on simple pneumoconiosis cases only). Films showing nodular-sized small opacities. 
revised radiological score on total years of exposure is 0.0117 , implying that for the same total amounts of coal and mineral dust in the lung, 50 years' extra exposure would raise the score by 0.585 unit. From Table $5,0.585$ unit is equivalent to the width of subcategory $1 / 1$. Rossiter and his colleagues also found the radiological score to be related to total years of exposure and approximately to the same extent.

(b) Age at death This shows a relation very similar to that of total years of exposure, although the correlation with the residual differences is slightly less at $0 \cdot 18(0.1>P>0.05)$. This is not surprising because of the high correlation $(0 \cdot 78)$ between age at death and years in the industry.

(c) Miners killed in pit accidents This group, similarly, has an average revised radiological score slightly less $(-0.13)$ than that expected from the relation to coal and minerals. Those killed in pit accidents died on average 15.6 years younger than the other miners and had worked for 11.7 years less, so that if there is some effect of age or years of exposure per se on radiological score, then the pit accident group would be expected to show a difference as found.

(d) Other variables The other variables examined were years since end of exposure to death, the interval between the date of the radiograph and the date of death, the size of the small opacities on the radiograph, the rank of coal mined, whether the miner was a coal getter or not, and whether nodules were palpable in the lung or not. For none of these was there much correlation with the deviations between the observed and expected revised radiological scores. For example, Fig. 12 shows how the deviations varied with whether the miner was a coal getter or not. The regression relations for the coal getters and other miners do not differ significantly, although there is slightly more scatter about the regression line for the other miners group.

\section{Progressive massive fibrosis}

As stated earlier, there were 23 films for which up to three readers recorded $X$ (possible P.M.F.), 18 for which up to three readers recorded A, B or C, and 35 for which four or more readers recorded A, B or C. For convenience, these have been called the doubtful, probable, and definite P.M.F. groups.

In Fig. 13 the observed revised radiological scores have been plotted against those expected on the basis of the relation to coal and mineral contents of the lung from the analysis of the homogeneous group of cases of simple pneumoconiosis. There is very wide scatter and a marked tendency for the background of simple pneumoconiosis to have been read higher than expected. This is most true for the definite P.M.F. group and least true for the doubtful group. The variances for the scatter for these doubtful
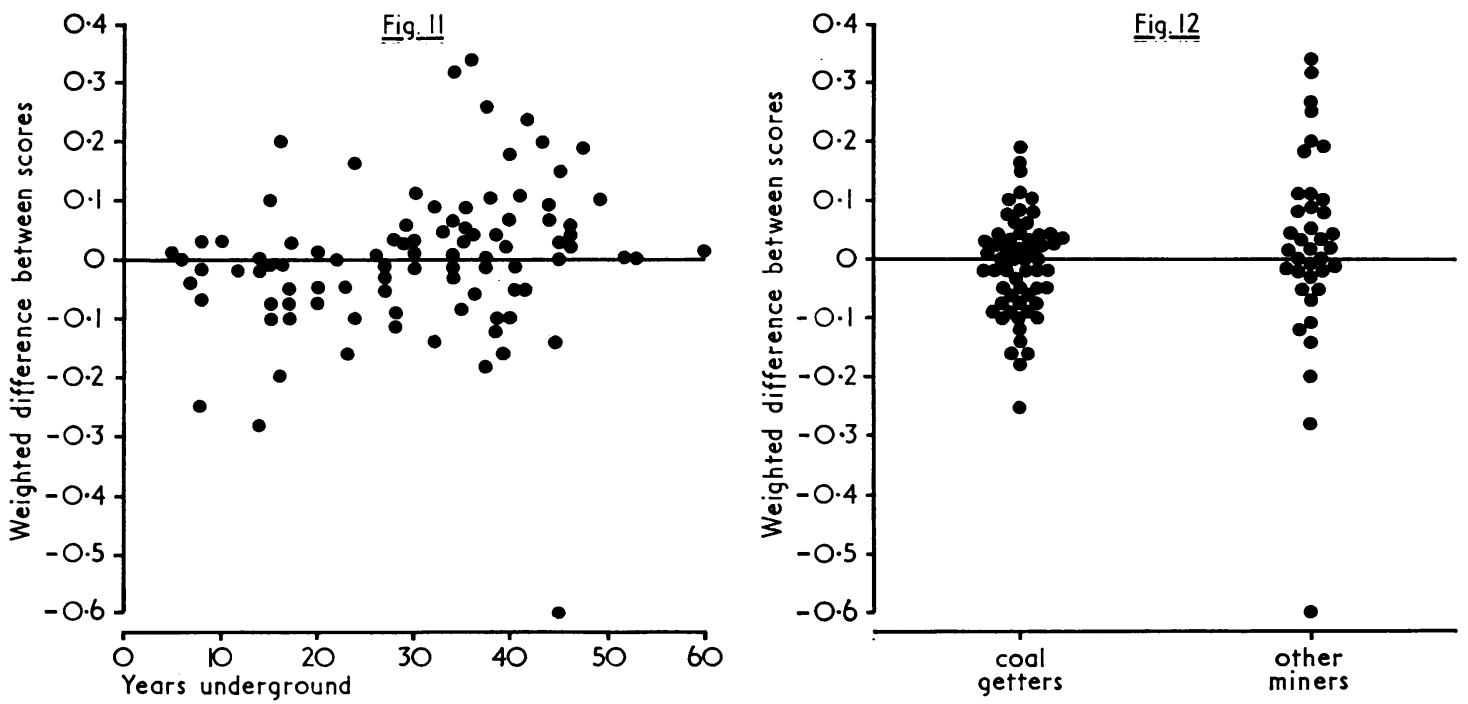

FIG. 11. Distribution of the differences between the observed radiological scores and those predicted from the relation to the coal and mineral contents for total years of exposure.

FIG. 12. Distribution of the differences between the observed radiological scores and those predicted from the relation to the coal and mineral contents for coal getters and other miners. 


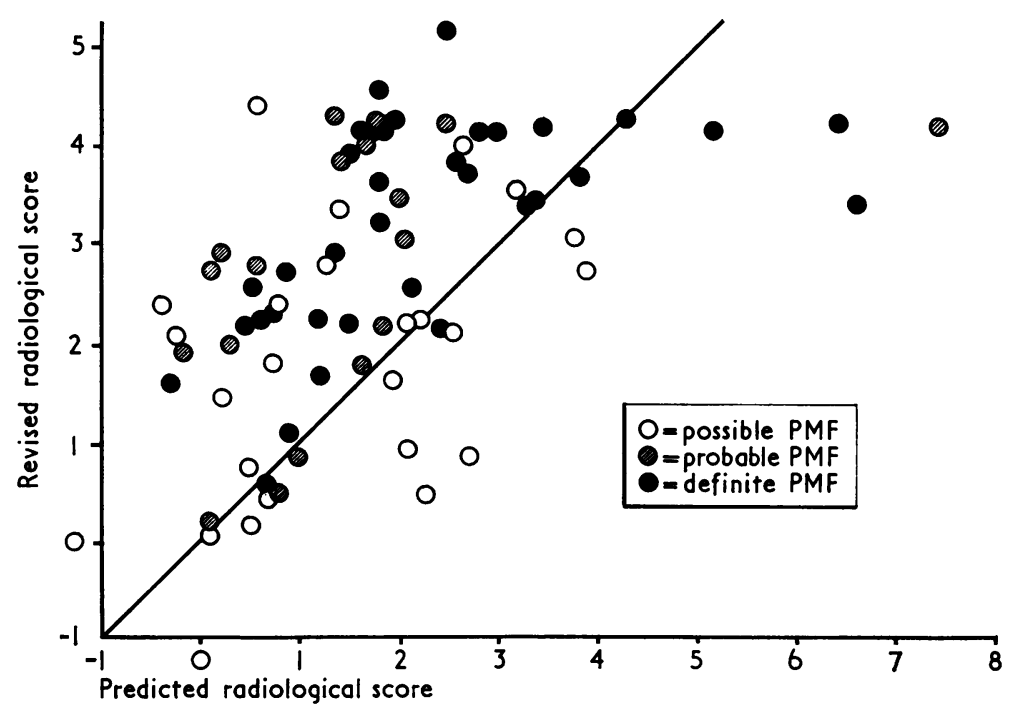

FIG. 13. Comparison of revised radiological scores for miners with P.M.F. with those predicted from the relation to the coal and mineral contents of the lungs (based on simple pneumoconiosis cases only).

probable, and definite P.M.F. groups are $2 \cdot 7,4 \cdot 6$, and 5.8 times as large as the residual variance of the simple pneumoconiosis group, and each of these variance ratios is significant at the 0.001 level.

Some of these came fro $\mathrm{m}$ Scotland or had nodular films or films of poor technique but this does not affect the conclusions. Each of the three groups can be subdivided by country (England, Wales, Scotland) and by the other two factors, giving 20 such subgroups. Of these 20, the variance is raised significantly in 15 even though the numbers are small in most of the subgroups.

\section{Discussion}

The principal analysis suggests that the simple hypothesis that radiological appearance of simple pneumoconiosis is related just to dust accumulation is tenable. The magnitudes of the contributions of the lung coal and mineral contents are compatible with the available information on their $x$-ray absorption characteristics, although much more work needs to be done, especially if high kilovoltage techniques (Jacobson, Bohlig, and Kiviluoto, 1970), now often used in Scandinavia and the U.S.A., become common in Britain.

In the previous papers in this series (Rivers et al., 1960; Rossiter et al., 1967) there were not enough cases to be able to make a detailed study of subgroups. The re-analysis with further cases has shown that the material is not homogeneous; the Scottish subjects and those with a nodular pattern of small opacities on the radiographs show peculiar relations between radiological appearance and dust content of the lungs.

The lung iron content is closely related to the coal and mineral contents. However, this relation for Scotland differs from that for the English and Welsh lungs. In particular, the regression coefficients of iron on coal content differ significantly, that for Scotland being 3.4 times as large. Bentley and Bergman (1970) have shown that the dust from these Scottish lungs generally consisted of very fine particles of soot with few or no particles of larger size. The source of this soot was considered to be the naked lights, that is, candles or oil in acetylene lamps that had been in use in Scottish pits where the risk of methane explosion was low.

The evidence from the relation of iron to the coal and mineral contents and the difference found for Scotland is compatible with the hypothesis that the source of the extra iron content of pneumoconiotic lungs is the iron-rich coating of the dust particles described by Collet and his colleagues (1967) which probably arises from phagocytosis. There is certainly a need to explore this inter-relation between iron and dust further.

The small number of films which showed small nodular opacities were read as having markedly higher radiological categories than would have been expected from the corresponding lung dust contents. This suggests that nodular opacities arise from some 
other cause, perhaps tissue reaction, than the simple dust accumulation mechanism, postulated for radiological appearance.

There is nothing unusual about the South Wales miners' lungs, except that they contain more coal and less mineral dust. This is as expected from a knowledge of the nature of the airborne dust which has a low mineral content and a high weight number ratio (Carver et al., 1962).

Although the different film readers varied in the level at which they recorded category 1 simple pneumoconiosis there was fortunately surprisingly general agreement as to the magnitude of the difference in amount of simple pneumoconiosis between the category boundaries. This finding has increased the validity of the analysis of this group of lungs using a large number of readers. It is also a validation of the use of a number of independent readings of a film which are then averaged to place the film more precisely on the continuum of radiological abnormality.

These studies could now be usefully carried further by looking at lungs in the early stages of simple pneumoconiosis and for which dust measurements and serial $x$-rays have been obtained during the last 10 to 15 years. Opportunities for doing this should be available in the N.C.B. Pneumoconiosis Field Research scheme.

This study could not have been carried out without the considerable help of many people. The chemical determinations were all done at the Safety in Mines Research Establishment. The initial pathology was carried out by many pathologists and the final assessments were made by Dr. D. Rivers. Drs. J. A. Dick, J. C. Gilson, D. J. Jones, D. C. Lindars, R. I. McCallum, J. B. Menzies, D. C. Morgan, L. J. G. Morgan, R. H. S. Pasqual, N. G. Pearson, S. Rae, and J. S. Washington were the film readers. Both the National Coal Board and the Pneumoconiosis Medical Panels provided chest radiographs and industrial histories. To all these people I am greatly indebted. I should also like to acknowledge the help and advice of my colleagues, both in this unit and elsewhere.

\section{References}

Bentley, R. A., and Bergman, I. (1970). Candle or oil soot as a cause of pneumoconiosis in coal miners. Ann. occup. Hyg., 13, 109-113.

Bergman, I. (1966). Determination of coal in formalin-fixed pneumoconiotic lungs. Analyt. Chem. (Wash.), 38, 441444.

- (1970). The relation of endogenous non-haem iron in formalin-fixed lungs to radiological grade of pneumoconiosis. Ann. occup. Hyg., 13, 163-169.

- , and Casswell, C. (1972). Lung dust composition of coalworkers in different coalfields in Great Britain. Brit. J. industr. Med., in press.

Burdekin, J. T., and Dawes, J. G. (1958). Some properties of airborne dust clouds in mining. Safety in Mines Research Establishment Research Report No. 149. Ministry of Power, London.
Carver, J., Nagelschmidt, G., Roach, S. A., Rossiter, C. E., and Wolff, H. S. (1962). The Conicycle, a portable gravimetric airborne dust sampling instrument and its preliminary calibration against the long-running thermal precipitator. Min. Engr., no. 21, pp. 601-619.

Cartwright, J. (1965). Relationships between mass and number concentrations of respirable airborne dust in British coal mines. Parts 1 and 2. Ann. occup. Hyg., 8, 193-206 and 257-264.

Casswell, C., Bergman, I., and Rossiter, C. E. (1971). The relation of radiological appearance in simple pneumoconiosis of coalworkers to the content and composition of the lung. Proceedings of the 3rd International Symposium on Inhaled Particles, London, 16-23 September 1970 , in press.

Collet, A., Martin, J. C., Normand-Reuet, C., and Policard, A. (1967). Recherches infra-structurales sur l'évolution des macrophages alvéolaires et leurs réactions aux poussières minérales. In: Davies, $C$. $N$. (ed.). Inhaled Particles and Vapours II: Proceedings of an International Symposium organized by the British Occupational Hygiene Society, Cambridge, 28 Sept.-1 Oct. 1965, 155-163. Pergamon Press, Oxford.

Cullen, T. J. (1962). Coherent scattered radiation internal standardization in X-ray spectrometric analysis of solutions. Analyt. Chem. (Wash.), 34, 812-814.

Einbrodt, H. J. (1965). Quantitative und qualitative Untersuchungen über die Staubretention in der menschlichen Lunge. Beitr. Silikose-Forsch., Heft 87.

Faulds, J. S., King, E. J., and Nagelschmidt, G. (1959). The dust content of the lungs of coal workers from Cumberland. Brit. J. industr. Med., 16, 43-50.

Gärtner, H., and Sommer, F. (1967). Experimentelle Untersuchungen über den Einfluss des Staubes auf die Entstehung des Röntgenbildes bei den Pneumokoniosen. Arch. Hyg. (Berl.), 151, 29-40.

Göbbeler, Th., Klosterkötter, W., Löhr, E., Magnus, L., and Scherer, E. (1968). Zur Frage der röntgenologischen Darstellbarkeit von Staubdepots in den Lungen. Untersuchungen am Alderson-Rando-Phantom. Beitr. SilikoseForsch., Heft 97, pp. 1-21.

Gordon, R. L., and Harris, G. W. (1956). Geiger-Müller counter equipment for quantitative X-ray diffraction analysis of powders. Safety in Mines Research Report No. 138, Ministry of Power, London.

Gough, J., James, W. R. L., and Wentworth, J. E. (1949). $A$ comparison of the radiological and pathological changes in coalworkers' pneumoconiosis. J. Fac. Radiol. (Lond.), 1, 28-60.

International Labour Office (1959). Meeting of experts on the international classification of radiographs of the pneumoconioses. Occup. Safety Hlth, 9, 63-69.

Jacobsen, M., Rae, S., Walton, W. H., and Rogan, J. M. (1970). The relation between pneumoconiosis and dust exposure in British coal mines. Paper presented at 3rd International Symposium on Inhaled Particles, London, Sept. 16-23, 1970.

Jacobson, G., Bohlig, H., and Kiviluoto, R. (1970). Essentials of chest radiography. Radiology, 95, 445-450.

King, E. J., and Gilchrist, M. (1945). Chronic pulmonary disease in South Wales coalminers. III Experimental studies. C. The estimation of coal and of aluminium in dried lung. Spec. Rep. Ser. med. Res. Coun. (Lond.), 250, pp. 21-28, H.M.S.O., London.

- Maguire, B. A., and Nagelschmidt, G. (1956). Further studies of the dust in lungs of coal-miners. Brit. $J$. industr. Med., 13, 9-23.

_, and Nagelschmidt, G. (1945). Chronic pulmonary disease in South Wales coalminers. III Experimental studies. B. The mineral content of the lungs of workers from the South Wales coalfield. Spec. Rep. Ser. med. Res. Coun. (Lond.), 250, pp. 1-20, H.M.S.O., London. 
Liddell, F. D. K. (1963). An experiment in film reading. Brit. J. industr. Med., 20, 300-312.

, and Lindars, D. C. (1969). An elaboration of the I.L.O. classification of simple pneumoconiosis. Brit. J. industr. Med., 26, 89-100.

Magnus, L., Göbbeler, Th., Löhr, E., Rassow, J., and Scherer, E. (1968). Der Einfluss von Asche-, Pyrit- und Kohlen-staubgehalt des Grubenstaubes auf die röntgenologische Abbildung. Untersuchungen am AldersonRando-Phantom. Fortschr. Röntgenstr., 108, 630-638.

Reisner, M. T. R. (1970). Results of epidemiological studies of pneumoconiosis in West German coal mines. Pape presented at 3rd International Symposium on Inhaled Particles, London, Sept. 16-23, 1970.

Rivers, D., Wise, M. E., King, E. J., and Nagelschmidt, G. (1960). Dust content, radiology, and pathology in simple pneumoconiosis of coalworkers. Brit.J. industr. Med., 17, 87-108.

Rossiter, C. E., Rivers, D., Bergman, I., Casswell, C., and Nagelschmidt, G. (1967). Dust content, radiology and pathology in simple pneumoconiosis of coalworkers (further report). In: Davies, C. N. (ed.). Inhaled Particles and Vapours II: Proceedings of an International Symposium organized by the British Occupational Hygiene Society, Cambridge, 28 Sept.-1 Oct. 1965, pp. 419-437. Pergamon Press, Oxford.
Safety in Mines Research Establishment (1963). Safety in Mines Research, 1962, Forty-first Annual Report, pp. 34-36, H.M.S.O., London.

UICC Committee (1970). UICC/Cincinnati classification of the radiographic appearances of pneumoconioses. Chest, $58,57-67$.

Vyskočil, J., Tůma, J., and Macek, M. (1970). Relationships between morphological changes and content of silica and hydroxyproline in bronchi and lungs of coal miners. Int. Arch. Arbeitsmed., 26, 157-166.

Wise, M. E., and Oldham, P. D. (1963a). Estimating progression of coal-workers' simple pneumoconiosis from readings of radiological categories. Brit. J. industr. Med., 20, 124-144.

$\longrightarrow$, and - (1963b). Effect of radiographic technique on readings of categories of simple pneumoconiosis. Brit. $J$. industr. Med., 20, 145-153.

Worth, G., Muysers, R., and Einbrodt, H. J. (1968). Über die Korrelationen von röntgenologischen, pathologischanatomischen und staubanalytischen Befunden bei der Kohlenbergarbeiterpneumokoniose. Beitr. SilikoseForsch., Heft 96, pp. 1-41.

Received for publication March 4, 1971. 